\title{
Reviewing ISO Compliant Multifunctionality Practices in Environmental Life Cycle Modeling
}

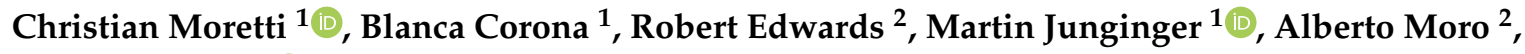 \\ Matteo Rocco ${ }^{3, *}$ (iD and Li Shen ${ }^{1}$ \\ 1 Copernicus Institute of Sustainable Development, Utrecht University, 3584 CB Utrecht, The Netherlands; \\ c.moretti@uu.nl (C.M.); b.c.coronabellostas@uu.nl (B.C.); h.m.Junginger@uu.nl (M.J.); l.shen@uu.nl (L.S.) \\ 2 Joint Research Centre, European Commission, 21027 Ispra, Italy; robert.edwards@ec.europa.eu (R.E.); \\ alberto.moro@ec.europa.eu (A.M.) \\ 3 Department of Energy, Politecnico di Milano, 21056 Milan, Italy \\ * Correspondence: matteovincenzo.rocco@polimi.it
}

Received: 27 May 2020; Accepted: 6 July 2020; Published: 11 July 2020

Abstract: The standard ISO 14044:2006 defines the hierarchical steps to follow when solving multifunctionality issues in life cycle assessment (LCA). However, the practical implementation of such a hierarchy has been debated for twenty-five years leading to different implementation practices from LCA practitioners. The first part of this study discussed the main steps where the ISO hierarchy has been implemented differently and explored current multifunctionality practices in peer-reviewed studies. A text-mining process was applied to quantitatively assess such practices in the 532 multifunctional case studies found in the literature. In the second part of the study, citation network analysis (CNA) was used to identify the major publications that influenced the development of the multifunctionality-debate in LCA, i.e., the key-route main path. The identified publications were then reviewed to detect the origins of the different practices and their underlying theories. Based on these insights, this study provided some "food for thought" on current practices to move towards consistent methodology. We believe that such an advancement is urgently needed for better positioning LCA as a tool for sustainability decision-making. In particular, consistent allocation practices could be especially beneficial in bioeconomy sectors, where production processes are usually multifunctional, and where current allocation practices are not harmonized yet.

Keywords: bibliometrics; review; life cycle assessment (LCA); allocation; system expansion

\section{Introduction}

Life cycle assessment (LCA) is supposed to be a standardized methodology to measure the life cycle impacts of products or services. LCA is currently ruled by ISO 14040:2006 and ISO 14044:2006 [1,2]; these standards have been the basis of the LCA methodology for the last two decades. Nevertheless, in the scientific community, some experts wonder if the detail presented in these standards is enough to guide LCA practitioners in practice [3-5].

One of the most debated problems in LCA is the so-called "multifunctionality" issue (or commonly, "allocation") [6-8]. Multifunctionality issues need to be dealt with when different product systems share a process, e.g., manufacturing processes delivering more than the studied product, or end-of-life activities providing both waste management service and a recovered or recycled product. In these cases, apportioning environmental burdens among the co-products, or rather co-functions, becomes necessary. According to ISO 14044:2006, multifunctionality should be solved by using the following three-level hierarchy [2]: 
1. Avoiding allocation by subdivision (dividing the unit process into two or more sub-processes) or system expansion ("expanding the product system to include the additional functions related to the co-products");

2. Allocation following underlying physical relationships (i.e., an allocation that quantitatively reflects how the inputs and outputs are changed by changes in the amount of each product of the system);

3. Allocation (partitioning) based on other relationships (e.g., economic value).

The same hierarchy applies also to "open-loop" recycling, i.e., when a material is recycled as a different product because it is no longer suitable to replace the original product directly. Only in such open-loop recycling, ISO 14044:2006 provides further guidance on the third level of the hierarchy, where physical properties (e.g., mass) are preferred to economic value, which in turn is preferred to the number of subsequent uses of the recycled material [2].

The existence of the ISO's multifunctionality hierarchy should avoid the use of inadequate approaches, e.g., determined by the interests of the stakeholders or the ones of the study's commissioner [3]. Nevertheless, the apparent lack of sufficient guidance has fed different implementation practices [9]. Consequently, although most LCAs claim compliance with the two ISO standards, practitioners have applied different allocation procedures in LCAs assessing the same or similar products [10]. Since the choice of the allocation method typically affects the outcome of the LCA significantly [6,10-13], this problem has led to different conclusions and therefore low reliability and robustness of the LCA results [14]. Moreover, due to the lack of a shared view in the LCA community, some authors decide not to follow the ISO hierarchy (see [15]), while other authors select the allocation method based on their subjective decision (see, e.g., [16] and [17]). Other researchers choose allocation methods that are "commonly" applied in similar case studies in the literature (see, e.g., [18]), others calculate also an average allocation parameter considering common parameters (e.g., [19]) or others use "conservative" allocation methods that provide the highest impacts (e.g., see [20]).

This article presents a literature review on the main practices and debates on using ISO 14044:2006 recommendations to solve multifunctionality problems. A critical literature review on multifunctionality methodology development was combined with quantitative analysis of current multifunctionality practices, and a bibliometric review based on citation network analysis (CNA). The quantitative analysis was performed by a text-mining process in 532 multifunctional case studies found in the literature.

The CNA was used to identify the main knowledge flow on multifunctionality in LCA, also known as "the main path". Tools and software based on the "main path" method are used for many applications: tracking the evolutionary trajectory of a science field or the development of a specific technology, or the evolving changes of legal opinions of courts [21,22]. The "main path" was investigated to detect the historical origins of the different practices currently present in the literature and their underlying theories. The use of such a tool overcomes some limitations of the traditional systematic reviews conducted so far on this topic, which were based on "human" selection of the articles (e.g., through criteria such as the number of citations).

In the literature, the definitions used to characterize the multifunctionality issue are not harmonized. For this reason, we provided Appendix A reporting the definitions used in this review to distinguish the different types of products, multifunctional processes, modeling approaches and system expansion approaches.

\section{Methodology}

Figure 1 summarizes the three main steps followed in this literature review. First, the literature search was performed. Second, a critical review was conducted to identify the main issues and bottlenecks in the LCA literature when implementing the ISO allocation procedures. The critical review was combined with a text-mining process to quantitatively assess the current practices in the LCA 
literature (focusing on all the LCA case studies selected by the query). Third, a bibliometric analysis was performed based on citation network analysis (CNA).

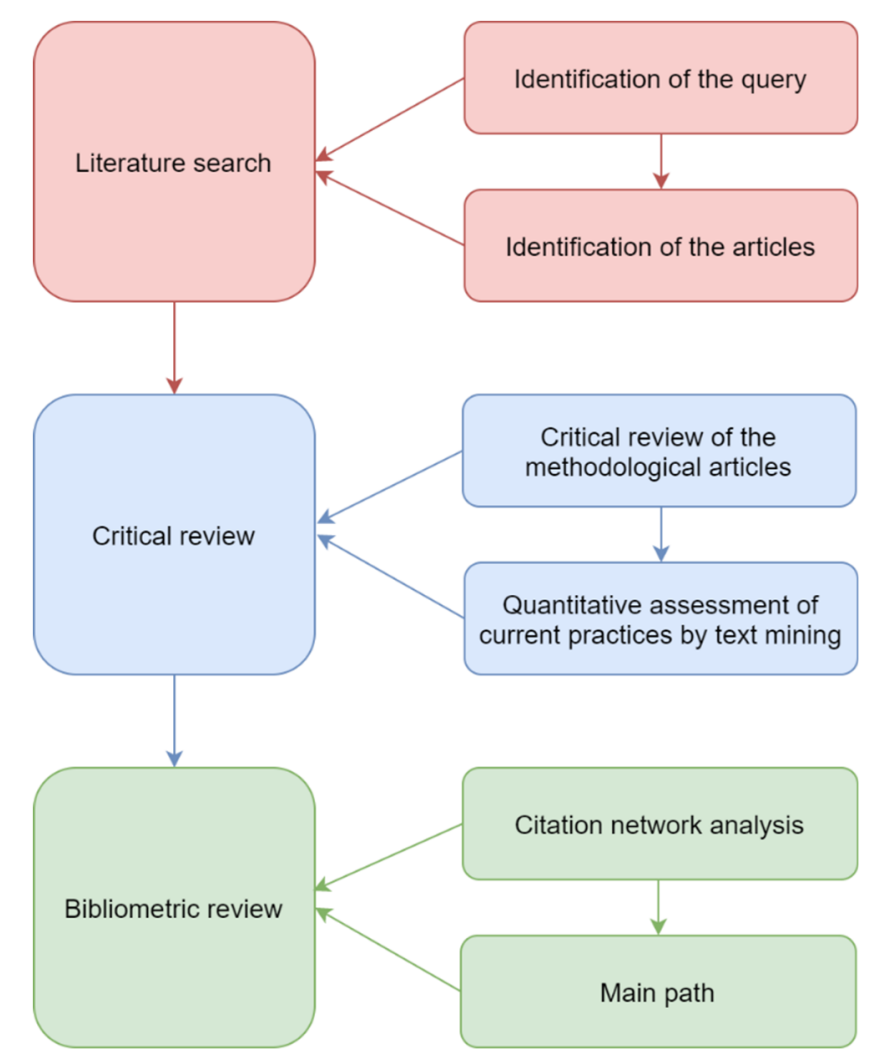

Figure 1. The three steps followed in the literature review.

The literature search was based on data collected from the Scopus database in February 2019. The searched publication fields were: title, abstract, and keywords. The search string was characterized by the terms: "Life Cycle Assessment", "LCA", "multifunctionality", "allocation" and "multi-output". Since allocation approaches are also used in other fields (e.g., in business management), the query was first limited to environmental assessment or engineering-related fields. Because of this, the documents were reduced from 1310 documents to 1152 . This allowed us to exclude 145 documents belonging to business management, 6 related to veterinary science and 7 others. Our analysis was further refined by considering articles only from the category of Scopus "journals". By applying this last adjustment, the articles resulting from the search became 930. Since only research articles were analyzed, some relevant books or conference proceedings may have been excluded from the analysis. Nevertheless, books often resume the contributions previously published as articles, and some excluded documents might have been considered by some of the reviewed reviews. Figure 2 shows the number of publications per year, highlighting the growing interest in the topic.

The corpus of documents on which the analyses were performed included the 930 articles retrieved from Scopus and the main LCA guides and standards, i.e., ISO technical reports and standards (also withdrawn ones like ISO 14041:1998) [23-26], the International Reference Life Cycle Data System (ILCD) handbook [27], the Product Environmental Footprint (PEF) guide [28] and the Product Environmental Footprint Category Rules (PEFCR) guidance [29]. Out of the 930 documents, 307 studies were identified through their title and abstract as "methodological articles" (of which 117 were review articles focusing on a specific sector where LCA is applied). These methodological articles focused either on the general methodological debate about multifunctionality procedures, or discussed a specific method, or introduced a new model to solve multifunctionality. The most relevant articles in this group were critically reviewed to understand the main issues when solving multifunctionality in LCA while 
claiming compliance with ISO. This critical review focused mainly on the articles cited more than 20 times ("most cited ones") and the articles published after 2015 ("recent ones").

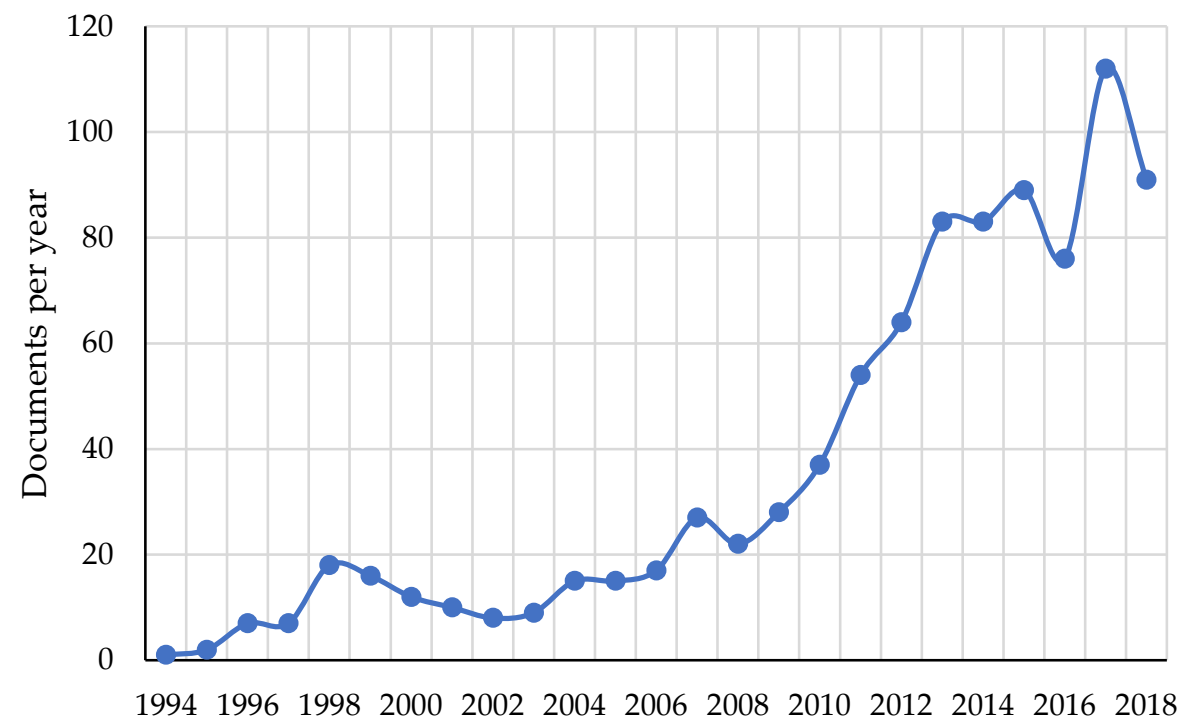

Figure 2. The time distribution of the articles on multifunctionality in LCA published in scientific journals per year retrieved from Scopus.

The critical review was combined with a text-mining process whose aim was to quantify the current practices when solving multifunctionality issues. The text-mining process was manually performed on the remaining 532 case studies. These 532 case studies resulted from a further refinement which excluded 91 articles that either did not apply full LCA or were not environmental LCA studies. Concerning the multifunctional case studies retrieved from the literature, we observed that specific parts of the bioeconomy namely agriculture (63 case studies), bioenergy (185), bio-based materials (52) and anaerobic digestion (21), were the ones most affected by the issue of multifunctionality together with related sectors namely aquaculture (14), dairy and meat products (79), fossil counterparts (34) and waste management (50). These sectors together represented $94 \%$ of the 532 case studies identified by the query.

Text-mining software can detect relevant terms or keywords in the corpus of literature with less time and cost than a person [30]. However, when the keywords represent technical concepts, dedicated software typically achieves low to medium efficiencies (e.g., 25\%-65\%) [30]. For instance, software could not understand when the concept "system expansion" was used as an alternative expression for substitution or for system enlargement. To increase the efficiency of the text-mining method, the quantitative estimation was performed directly by the analyst. When the terms representing the concepts of interest (e.g., "allocation") were encountered, the context of their use was assessed by reading the surrounding text.

In the third step, i.e., the bibliometric review, the 930 articles were investigated by CNA. The CNA was performed using Pajek software [31]. Documents are considered "nodes" and the citations are the "links" between these documents. The type of nodes is defined therefore based on the type of document. The "sources" are the documents that are cited but cite no other documents and therefore represent the origins of the knowledge. The "sinks" are the documents that cite other documents but are not cited and therefore could represent the "current stage" of the knowledge stream. Intermediate documents cite other previous documents and are also cited by more recent documents [21]. Our CNA aimed at identifying the main path of research. This path represents the main knowledge flow in a specific topic, i.e., the major contributions that have influenced the development of the research, which does not mean directly the most cited ones overall $[32,33]$. The main path was obtained by using an algorithm that computed what citations between articles had been more significant. In particular, such a significance 
was calculated through the key-route method [34]. This method identifies the main chain of articles by considering the highest transversal count $[33,34]$. The transversal counts measure the significance of a citation link, i.e., by counting the times a citation link is traversed [34]. The transversal count adopted was the search path count (SPC). The SPC assigns as value to each link the number of paths traversing the link among all possible paths connecting all the sources to all the sinks [21,22].

\section{The Critical Review Combined with Text Mining}

When critically reviewing the methodological articles on multifunctionality, it emerged that these articles present two main "debates" regarding ISO-compliance practices. These two debates concern the application of system expansion (explained in Section 3.1 and related sub-Sections) and the identification of relevant partitioning criteria (see Section 3.2). In particular, Pelletier et al. (2015) identified three "schools" distinguished by the way they interpret the ISO hierarchy with respect to these three aspects: (1) the consequential LCA (CLCA) thinking school interprets system expansion as substitution, (2) the natural-science attributional school applies system expansion as enlargement and prioritizes allocation based on a physical parameter, and (3) the socio-economic attributional school applies system expansion as enlargement but prefers economic allocation. According to Pelletier et al. [9], these three schools are "internally consistent" but "mutually exclusive".

\subsection{Debate on the Interpretation of ISO's System Expansion}

The system expansion debate focuses on how and when the substitution method should be applied. ISO 14044:2006 recommends system expansion as a way to avoid allocation, but no further specification is provided regarding the differences between enlargement and substitution (see Appendix A for detailed definitions), and about its implementation in attributional or consequential LCAs. Substitution is often used as a system expansion approach in attributional LCAs (ALCAs), which is not perceived as correct by many LCA experts [5,9,35-38]. According to these practitioners, ALCA modeling should not rely on perturbation logic or counterfactual notions, such as substitution or avoidance of other products/processes (as also highlighted, e.g., by Majeau-Bettez et al. [35]). It is argued that the sum of the impacts accounted by attributional LCAs should add up to the worldwide impacts, and this would not be valid anymore if substitution were applied [5,39]. For this reason, Chen et al. (2010) concluded that the "allocation methods, even if perfectible, are still preferable to the system expansion method" (used as synonymous of substitution), because "system expansion does not ensure a global coherency between various LCA studies" [40]. On this basis, the use of substitution as a system expansion method in ALCA is not supported by any of the schools of interpretation identified by Pelletier et al. [9]. Similarly, Bailis and Kavlak, after applying substitution for the by-products of a biofuel, concluded that "the large disparity between system expansion and other methods raises questions about the validity of system expansion" [41]. Concerning system expansion by enlargement, this cannot be applied when the goal of the study requires the impacts of just one of the co-products or by-products to be obtained. In these cases, allocation cannot be avoided. For example, "In a milk production system that also produces beef, system expansion without substituting would lead to a system with a function of delivering both milk and beef" [42].

Other authors argue that ISO 14044:2006 does not acknowledge substitution as a system expansion approach. The reason is that ISO refers only to the addition of functions (i.e., enlargement) and not to the substitution of functions [3,5,43-45]. On these bases, several authors argue that a distinction of ALCA/CLCA should be present in future ISO $14044[9,46]$ since, for them, this distinction is crucial to select the appropriate system expansion method (enlargement or substitution) (as also pointed out by $[47,48])$. By contrast, other authors argue the opposite, i.e., that substitution is generally recognized as a valid method for avoiding allocation within attributional LCA $[49,50]$. For many practitioners, substitution is considered as synonymous with system expansion [51,52]. Under this argument and considering the ISO hierarchy, substitution should be preferred to any allocation method [53-57]. Pelletier et al. [9] suggested that the equivalence substitution-system expansion might have originated 
in a 1994 study authored by Tillman et al. [58]. The reason was that Tillman et al. [58] is a frequent citation when justifying the equivalence of substitution with system expansion. However, their study was published prior to the publication of the ISO standards.

\subsubsection{Current Practices in Specifying the Modeling Approach}

Although the choice of modeling approach (ALCA or CLCA), which depends on the goal, clearly determines the outcome of an LCA study, our text-mining process found that the keywords "attributional" and "consequential" were missing in 75\% of the LCAs involving multifunctional systems (see Figure 3 for a detailed breakdown, per product sector). This percentage refers only to the portion of articles published after 2004 when the term consequential LCA was clearly established (see Section 4.3). There are several possible reasons for this low specification rate of the modeling approach: (1) practitioners could still not be aware of the relevance to differentiate between consequential and attributional approaches, (2) practitioners may not specify the modeling approach because it is a direct consequence of the goal description, (3) they may not agree with a strict distinction between ALCA and CLCA, (4) they may be strictly following current ISO standards that do not distinguish between the two approaches or (5) they may have followed the recommendations of a policy directive or national/international guide that does not make such a distinction. Actually, some ALCA studies combined with consequential thinking are emerging [10]. These approaches aim mainly at accounting for some specific counterfactual effects or credits, and at the same time, limit complexity and uncertainties [59].

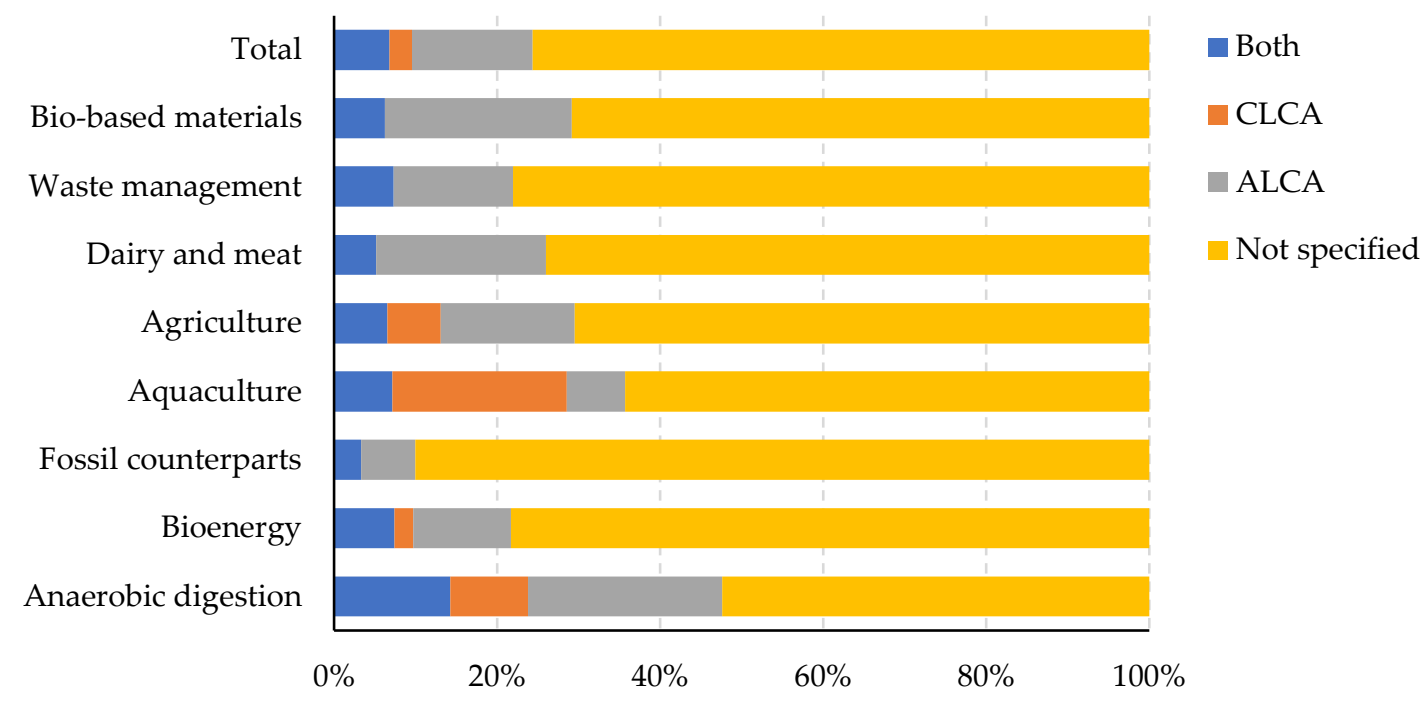

Figure 3. Percentage of articles which applied on the same case study both CLCA and ALCA approaches (Both), self-declared attributional studies (ALCA), self-declared consequential studies (CLCA) and studies which did not declare the approach followed (Not specified). Only case studies published after 2004 were considered (504).

The text-mining process found that $31 \%$ of the self-declared ALCA studies (using the keyword "attributional") used substitution as a system expansion approach to avoid allocation. However, this percentage varies depending on the sector under consideration, ranging from $19 \%$ to $45 \%$ (see Figure 4). The highest rate of substitution approaches in ALCAs was found in studies related to bio-based materials $(45 \%)$. On the other hand, there are few LCAs investigating fossil products that self-declared as attributional studies. The reason might be that substitution is rarely an option for fossil products since they are usually the "substituted products". 


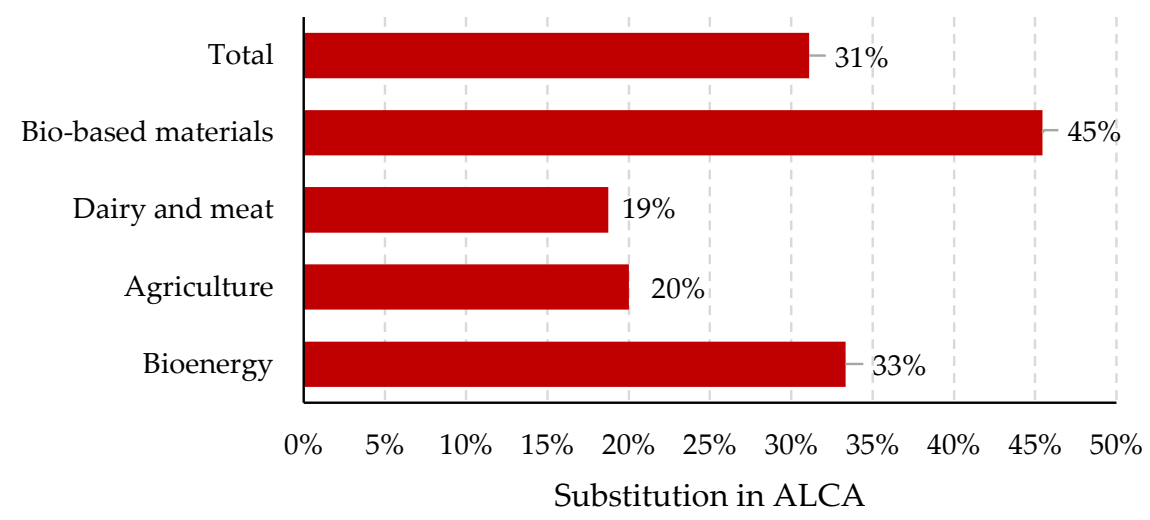

Figure 4. Percentages of self-declared attributional studies (ALCAs) which applied substitution as a system expansion approach. Only the sectors with a significant amount (more than 10) of self-declared attributional studies are included in this graph.

\subsubsection{The Application of Substitution as System Expansion Method}

Beyond the use of substitution in ALCA, two other critical aspects of substitution have been discussed in the LCA methodological articles. First, the high uncertainties introduced by the use of the substitution approach since it can lead to different results depending on the choice of substituted and/or substituting by-product $[3,60,61]$. A sensitivity analysis should be therefore recommended. Second, when substitution is suitable, the substitution of co-products should be avoided by checking the physical/economical significance of the products delivered by the multifunctional process [3,27]. However, some authors (for example [3]) argue that the importance of the co-products' physical significance is not emphasized enough in ISO 14044:2006 and the ILCD handbook. When physical significance is not checked and a by-product is credited for the replacement of co-products, the practitioner could obtain significantly distorted results [3,62]. A common practice to account for physical significance is to select the primary functions based on the main source of revenues $[35,63]$. In cases where the primary co-function(s) cannot be directly identified, the ILCD handbook proposes that they should be assumed to be those that jointly contribute to more than $50 \%$ of the combined market value of all co-functions of the analyzed multifunctional process [27].

Clear rules for differentiating by-products from the co-products are important, because, in substitution, all the credits from substituting by-products are attributed to the main co-product. If another LCA on the same process is made in which a by-product is considered to be the main product, the impacts of the process "get counted twice", so that the impacts for different products no longer add up to the total for the process (this would be a problem in an attributional model-for further details see the next Section).

\subsubsection{Using Substitution as the Allocation Method}

Another point of debate is the use of substitution for allocation (and not as a system expansion method). This type of allocation has been mentioned in the literature with different names, such as substitution-based allocation [9] and "proxy-based disaggregation" by substitution [35] and various versions of this method have been proposed (e.g., see Hermansson et al. who applied two different versions of this method to assess Kraft lignin [64]). By many practitioners, this option is perceived as the attributional way of using substitution. PEFCR guidance and PEF guide [28,29] propose that, when a by-product of a multifunctional system directly substitutes another product, such substitution might be considered as an allocation reflecting physical relationships. When this is the case, such substitution has to be based on a direct and empirically demonstrable relationship [28,65]. Pelletier et al. [65] stated that this is different from substitution based on marginal market models applied in consequential LCAs [65]. An example of such a substitution is when "manure nitrogen is applied to agricultural land, directly substituting an equivalent amount of the specific fertilizer nitrogen that the farmer would otherwise 
have applied" [28,65]. Hence, it is assumed that the impact caused in the system by the production of the substituted by-product corresponds to the impact of the production of the replaced product (as shown in [66]). With substitution, the impact of a by-product should equal that of the product it substitutes, and so is independent on the actual process that produces it. Moreover, the application of this substitution-based allocation can lead to a negative impact that in ALCA would mean that the model has been built inconsistently [35]. As an example, this happens when the wrong product is chosen as the main product of the multifunctional system [66] or the substituted product is not a minor product, even if representing less than $50 \%$ of market value [67]. Even if the substituted co-products are chosen carefully (i.e., they represent small percentages in physical and economical terms), this method sometimes fails in ALCAs assessing multiple impact categories, resulting in negative impacts for some of them [13,67]. Moreover, PEFCR guidance and PEF guide [28,29] also allow the possibility of using indirect substitution as a form of allocation based on "other relationship". "Indirect substitution may be modeled as a form of allocation based on some other relationship when a co-product is assumed to displace a marginal or average market-equivalent product via market-mediated processes" [28].

\subsection{Selection of the ISO Allocation Criterion}

The main discussion on the allocation criterion concerns the nature of the so-called ISO "physical relationships" and "other relationships" [7,42].

The authors in line with the socio-economic school argue that allocation can be based on physical relationships only when the ratio of the output products can be varied since this allows the establishment of physical causality between functional units by mathematical modeling [68-73]. For example, Bernier et al. [74] assessed the impact of Kraft lignin and applied the physical causality principle to allocate the impact between pulp and lignin "by varying the quantity of lignin precipitated and then observing direct variations in the environmental loads". They also specified that this type of allocation was selected based on ISO standards, which recommends this type of allocation over allocation based on mass, energy or economic values. This school, therefore, interprets "physical relationships" as "physical causality relationships" and interpret "other relationships (e.g., economic value)" as "other causal relationships". Accordingly, they consider the allocation by other relationships as the only possible approach when it is not possible to change the ratio of production of the functional outputs of the system $[69,72]$. The practitioners following the view of this school often argue that, at this level, economic allocation is the recommended option, and only when it is not possible to use economic allocation, the allocation can be based on a physical parameter that should be selected based on the best proxy for economic revenues (e.g., see [7]). For example, this happens when there is a lack of market prices for one specific product [75]. However, the approximations of these causal relationships have always been a debated scientific issue [76]. For example, these relationships can be based on the common function of all co-products (as done by [77]).

The text-mining process revealed that only $28 \%$ of the LCA case studies selected an allocation method based on ISO relationships interpreted as "causal relationships". The percentage of studies following this interpretation varied significantly depending on the sectors considered (see Figure 5). In particular, it was very low in the studies focusing on anaerobic digestion, bioenergy and bio-based materials $(5 \%-16 \%)$. On the other hand, this interpretation is largely present in the fossil fuels sector, where the allocation of emissions to single products is often based on linear programming models calculating marginal emissions by varying the amount of functional units $[78,79]$. Another example where this interpretation is largely present is in the dairy sector. The main reason is that many practitioners assessing dairy products often selected their allocation choice based on the recommendations of the International Dairy Federation [80], which adopts this interpretation. 


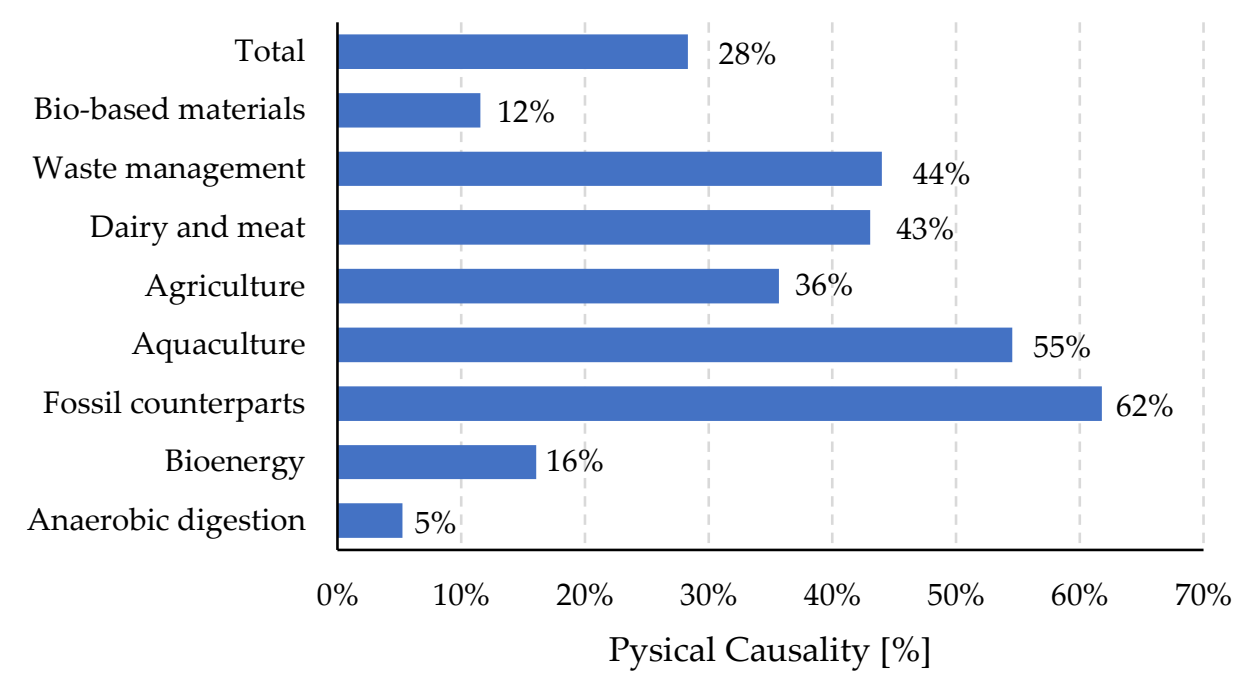

Figure 5. The percentage of studies in each research area that used causality as the principle for the allocation choices per (sub-)cluster and overall. The number of studies per sector: anaerobic digestion (21), bioenergy (185), fossil counterparts (34), agriculture (63), aquaculture (14), dairy and meat (79), waste management (50), bio-based materials (52).

Conversely, the practitioners belonging to the natural-science school often refer to an allocation by physical parameter as ISO-second level allocation by interpreting "physical relationships" as allocation based on a physical parameter, e.g., mass or energy value [8,16,81-83]. On this basis, they prefer allocation based on a physical parameter (e.g., mass) over economic allocation because "ISO 14044 standard mentions economic allocation when no other possibility is available" [84]. The economic allocation may be selected by the practitioners following this view if allocation based on physical parameter "result in the attribution of a large proportion of burdens to low-value co-products" [9]. The same school often argued that an allocation based on a physical parameter is preferred over economic allocation since it is not affected by price fluctuations $[82,85]$. As a response, authors in line with the socio-economic school argue that the price fluctuation is not the important parameter for the allocation method, but the ratio of prices among all products, which is much less variable because it mainly depends on the fluctuating price of the common inputs to the process [86].

The preference expressed by the natural-science school is adopted by PEFCR guidance and PEF guide, which prefer allocation based on physical keys (e.g., mass or energy) to economic ones [28,29]. In the PEF guide, ISO "physical relationships" might have been interpreted as allocation based on physical parameters (this emerges from our understanding of annex X of PEF guide), leading to the preference for physical allocation keys. On the contrary, the ILCD handbook adopts the interpretation of "ISO physical relationships" from the socio-economic school and states that only when it is not possible to find clear physical causal relationships between the co-functions, allocation based on economic relationships can be used [27]. However, differently from what is usually preferred by the socio-economic school, the ILCD handbook does not give preference to economic allocation over non-causal physical properties such as energy content [27]. The ILCD handbook also adds a footnote to remark that energy allocation is not an allocation based on ISO causal physical relationship but a simplified allocation based on a physical property that is not causal [27].

To make an example of the implication of adopting one interpretation or the other, we can consider a biorefinery example that produces fuels (e.g., ethanol) and chemicals for materials (e.g., lactic acid) [87]. The natural-science school would prefer energy or mass allocation (considered by them as ISO second level) over economic allocation (considered ISO third level). Conversely, the socio-economic school would prefer economic allocation, arguing that mass and energy allocations (all considered ISO third level) are meaningless for such a biorefinery because of not representing any causality mechanism. They would also argue that it is not appropriate to use energy allocation when not all the co-products 
are used for their energy content or to use mass allocation when there are energy products among the co-products.

\section{The Bibliometric Review Based on Main Path Analysis}

The main path of research identified using CNA is shown in Figure 6 and included 21 articles. The evolution of the multifunctionality discussion in the scientific community can be divided into four periods, which have been defined as (1) bilateral beginning, (2) the ISO 14041 influence, (3) consequential LCA influence, and (4) ISO 14044 application.

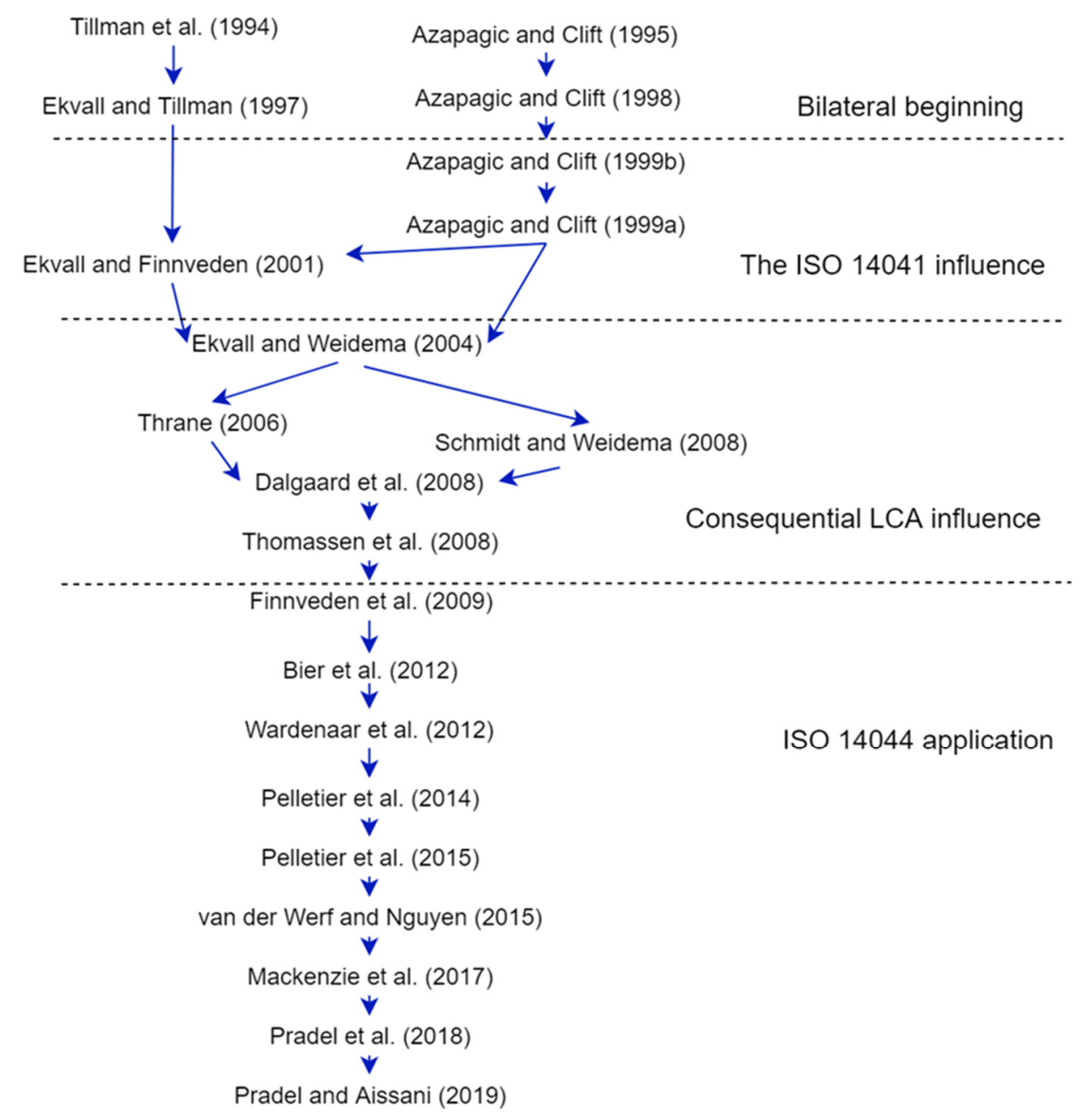

Figure 6. The key-route main path of research on LCA multifunctionality (output from Pajek calculations), obtained from the citation network analysis.

\subsection{Bilateral Beginning (1994-1998)}

The discussions on the LCA multifunctionality issue were initially developed following two parallel routes (see Figure 6). On the first route, Tillman, Ekvall and their co-authors developed different types of allocation methods for multi-output systems and open-loop recycling $[58,88]$. It is crucial to notice that at that time, the ISO 14041 was not yet released [25]. Tillman et al. [58] focused their article on the choice of system boundaries based on the purpose of an LCA. They defined three LCA purposes: 1) process tree (PT), today known as ALCA and applied to processes where there are one main product and some by-products, 2) technological whole system (TWS), similar to what today is known as ALCA and applied to processes delivering several co-products, and 3) socio-economic whole system (SWS), similar to current CLCA [58]. In this article, the word expansion was used once with 
respect to SWS, indicating that such a system accounts for economic and social factors and therefore "may lead to further expansion of the system" [58]. In 1994 and 1996, two conferences were held with sessions on allocation and life cycle inventory. Clift, who was also co-author of the publications in the second parallel route, published the reports of such sessions $[89,90]$. These reports concluded that allocation must, when possible, be based on causal relationships. Ekvall and Tillman discussed this conclusion, arguing that causal relationships could be either cause-oriented or effect-oriented [88]. An example of the first one is the manufacture of a product that occurs because the company expects customers to be willing to pay for it (cause). An example of an effect-oriented relationship is a system delivering a recycled product, which reduces the amount of virgin product in another system (effect). This second type of relationship resembles the current CLCA thinking. To represent effect-oriented relationships, they argue that the effects of the investigated product on other life cycles can be included in the LCA through the expansion of system boundaries. As the expansion of the system boundaries, they cited the approach developed by Tillman et al. (1994), which today is known as "substitution". Moreover, they argued that when LCA is used as a tool for decision support, the allocation procedure should generally be effect-oriented rather than cause-oriented. Therefore, it is possible to identify the probable origin of the consequential school in the study of 1997 of Ekvall and Tillman [88] and the study of 1994 of Tillman et al. [58].

The four articles of the second route were authored by Azapagic and Clift. In the first article (1995), they proposed linear programming (LP) modeling to solve the multifunctionality issue and to calculate the optimized environmental impact of plastic resins production, such as polypropylene and polystyrene [91]. The inputs and outputs of the system are then allocated to each of the co- and by-products through marginal changes in its production [91]. The marginal allocation coefficients correspond to the variation of the environmental burdens associated with a marginal variation of one of the co-functions [91]. The second article (1998) focused as well on LP as a tool for solving the problem of allocation and was applied to systems producing borate products. They highlighted that 1) "the main characteristic of this kind of modeling is that it is based on physical and technical relationships between the inputs and outputs [ ... ] describing the underlying physical causation in the system" [73] and 2) that the allocation by causal relationships provided by the model is obtained "by exploring how the burdens change when the quantity of one function is changed with the quantities of all the other functions kept constant" [73]. These changes can be marginal, incremental, or average ones; however, LP can only be applied when system behavior can be linearized, which does not usually happen in average changes (i.e., substantial changes as for example the elimination of a functional output completely) [73].

In 1996, the first draft [92] of the ISO hierarchy for solving multifunctionality was released, as reported by Ekvall and Tillman [88]. This hierarchy was very similar to the one still present in the current ISO 14044:2006. System expansion was indicated in the first level [92]: "by expanding the system boundaries so that inputs, outputs and recycles remain within the system" (retrieved from [88]). From the literal statement, it appears clear that it was intended as an enlargement of the system boundaries to include all the co-functions within the boundaries (see Figure A1 in Appendix A). Such an approach is different from the system expansion method (substitution) indicated by Tillman's SWS, where functions are avoided instead of added.

On the second level, it was stated [92]: "where allocation cannot be avoided, the allocation should be based on the way in which the inputs and outputs are changed by quantitative changes in the products or functions delivered by the system" (retrieved from [88]). There was no use of the term "physical relationships" as in ISO 14044:2006. Hence, ISO was proposing allocation methods such as the marginal allocation developed by Azapagic and Clift [91], which are based on quantitative changes in the products or functions delivered by the system.

Finally, the last level allowed the allocation of different functions based on economic relationships, excluding allocation by physical properties. This preference for economic values could be due to their cause-oriented essence (the function is provided because one is willing to pay for it). Based on the 
analysis of this bilateral beginning and this ISO draft [92], it seems that the socio-economic ALCA school represents the first version of the ISO hierarchy. In fact, they distinguish themselves by applying system expansion by only adding (and not subtracting) functions, and preferring economic allocation to an allocation based on a physical parameter (excluded option by this first draft version).

\subsection{The ISO 14041 Influence (1999-2003)}

In the third article of the second route, Azapagic and Clift used the boron product system to examine the different allocation methods recommended by ISO 14041, which was just released in 1998 [25,93]. ISO 14041:1998 introduced the same three levels of the hierarchy of the present ISO 14044:2006. However, the second level included the following clarification: "the resulting allocation will not necessarily be in proportion to any simple measurement such as mass or molar flows of coproducts". Azapagic and Clift argued that, following ISO 14041, allocation by physical (causal) relationships had to be the result of mathematical system modeling [70,93]. Nevertheless, the ISO 14041 allocation underlying physical relationships allowed also allocations based on the "cause of the limits" of the amount of product output. This aspect emerges from the annex of ISO 14041:1998, where mass or volume allocations are suggested as representing physical relationships for road transportation because the quantity of materials transported is limited by the maximum load that the vehicle can carry [25]. Although these two approaches may at first appear contradictory, they are in line with Azapagic and Clift's work, who also concluded that in some cases (which include the transportation example), allocating based on a physical quantity leads to the same results obtained by marginal allocation [70,93]. In these cases, it may be correct to allocate based on a physical parameter representing the physical causation involved, and therefore, not arbitrarily [70,93].

Azapagic and Clift (1999a) highlighted that system expansion (enlargement) is not always applicable. This approach is not possible when the goal of the study requires to determine the impacts of only one of the products [93]. The reason is that, by expanding the functional unit to include the co-functions, the results at the level of one single product would not be available. They also investigated allocation in heat and power cogeneration plants. Due to lack of data, they could not model the system to represent physical causalities and therefore applied the "avoided burdens approach" (in later research "substitution"). Azapagic and Clift argued that substitution is a conceptually equivalent alternative to system expansion, and is suitable when one co-product displaces its production elsewhere, such as for energy recovery from waste or cogeneration [93].

Actually, annex B of ISO 14041 quoted the same example of system-expansion/substitution applied to energy from waste incineration [25]. Nevertheless, annex B specified that the expansion of the boundaries like this requires 1) that the goal of the study is aimed at assessing a change, "i.e., a comparison between two alternative scenarios for the same product" and 2) that the modeled change which will actually occur because of the decision supported by the LCA can be predicted with a fair degree of certainty [25]. To apply this type of expansion, the LCA should aim, therefore, to answer the question of what would have been the long-term marginal effect if the service had not been performed [25]. Hence, substitution became a possible system expansion approach in what nowadays is understood as consequential thinking. This annex with allocation examples is no more included in the current ISO 14044:2006.

In the lowest level of the allocation hierarchy of ISO 14041 [25], economic allocation became an example, and no more the only acknowledged allocation method as it was reported in the previous draft version [92]. Hence, in some cases, allocation based on a physical parameter could be preferred to an economic allocation, and this might have given birth to the natural-science ALCA school. Moreover, ISO 14041:1998 specified that the environmental impact should be allocated only to the products causing the release of the emissions (causality principle). ISO 14041:1998 proposed the example of a multi-input incineration process releasing cadmium emissions which should be allocated only to the input wastes that contain cadmium. 
The fourth article [70] referred once again to LP-based marginal allocation, stating that this modeling applies "when the functional outputs can be varied independently", i.e., in partial joint production or combined production (see Appendix A for more details about these definitions). A naphtha cracking was proposed as an example of a system where the outputs can be independently varied (within physical and thermodynamic limits) by changing the operating conditions [70]. When that is not the case (i.e., full joint production; with a fixed ratio of products), "allocation by physical causality cannot be implemented" [70]. Linked to this impossibility, they provided the often-cited example of the ratio of sodium hydroxide $(\mathrm{NaOH})$ and chlorine $(\mathrm{Cl} 2)$ produced by electrolyzing brine, which is fixed by stoichiometry. Other examples that they mentioned about this impossibility are rapeseed oil/residue (ratio fixed by the chemical structure of the plant) and beef/leather (fixed by the physical structure of the animal) [70]. In these cases, the authors stated that ISO recommended economic allocation because it reflects "the socio-economic demands which cause the multiple-function systems to exist" [70]. They concluded that "allocation on an arbitrary basis, such as mass or energy flow, must be avoided" and "where physical causality between functional units and environmental burdens exists, the allocation should always be based on these causal relationships" [70]. The authors based their methodological choices on the 1997 voting draft of ISO 14041.

The ISO 14041:1998 was complemented by ISO/TR 14049:2000 [23]. This technical report defined system expansion as the addition of functions but lost the concept of system expansion with substitution when the goal is to assess a change. This is still missing in the current ISO 14044:2006 and ISO/TR 14049:2012 [2,24].

This ISO/TR provided two examples related to the disposal phase of the life cycle. The first example showed how to expand boundaries to compare two processes with different outputs, A and B, using the same inputs. As illustrated in case d of Figure A1 in Appendix A, the system boundary for each process needs to be expanded with an alternative process for making the other product. Then the two systems under comparison produce the same functional unit $\mathrm{A}+\mathrm{B}$. Moreover, it specified that the added processes shall be those that "would actually be involved when switching between the two analyzed systems" [23]. In the second example, open-loop recycling is solved with a closed-loop procedure that includes the entire recycling processes into the same system boundaries (like case c of Figure A1 in Appendix A).

Concerning allocation by physical property (e.g., mass or viscosity), ISO/TR 14049:2000 [23] emphasized that this type of allocation should be preferred to economic allocation only when it reflects the way in which the inputs and outputs are changed by quantitative changes in the products, (as, for example, in the transportation example in ISO 14041:1998, quoted above). This had to be proven by varying the ratio of co-products [23].

In 2001, Ekvall and Finnveden published a critical review on allocation in ISO 14041:1998 [72]. Ekvall and Finnveden stated that system expansion (in the form of substitution) could be used in a broader range of LCA goals than the one for which it is recommended by the annex of ISO 14041. For example, it can be used to account for indirect effects [72], similar to how the substitution method is used today in CLCAs.

In the same review, Ekvall and Finnveden (2001) identified the marginal allocation of [70] as a method corresponding to the second level in the ISO hierarchy (the first connection between the two parallel routes in Figure 6). In particular, Ekvall and Finnveden [72] explained that there were two possible interpretations for ISO allocation based on physical-causal relationships. Under the first interpretation, the "environmental burdens allocated to a function should be the burdens avoided if that function is no more delivered while the other functions are unaffected" [72]. This type of allocation is applicable when the environmental burdens are linear with the quantity of each of the functions delivered and, therefore, it is possible to eliminate the functions independently [72]. The second interpretation is that "the environmental burdens allocated to each of the functions should be proportional to the partial derivatives at the point of operation" [72]. This is a generalized description of the LP modeling of Azapagic and Clift. 
Concerning the third level of ISO hierarchy, they emphasize that a rigorous interpretation of the standard leads to an allocation based on other causal relationships, e.g., economic value, and not in non-causal relationships (e.g., allocation based on "arbitrary physical property of the products such as mass, volume or energy content") [72]. As aforementioned, this strict approach was also the only one foreseen in the first draft of ISO hierarchy [92] and favored by the ALCA socio-economic school. At this point, the main path stopped to be bilateral and started a period of interconnection that led to the development and definition of what today is categorized as "consequential thinking".

\subsection{Consequential LCA Influence (2004-2008)}

In 2004, the keyword consequential LCA appeared for the first time on the main path [94]. In the same article, Ekvall and Weidema delineated the consequential LCA as commonly defined today. They stated that CLCA avoids allocation by applying substitution-type system expansion, using marginal data [94].

Following the main path of research, we found several articles on CLCA case studies. In the first article, Thrane conducted a CLCA of fish products [95]. The second article authored by Schmidt and Weidema [96] is focused on how to identify the marginal vegetable oil to be substituted in a CLCA of agricultural systems providing food and oil. Thrane [95] pointed out that, generally, the ISO allocation hierarchy can also be considered valid for CLCA. In fact, when system expansion (either by enlargement or by substitution) or subdivision is not applicable, it is also necessary to allocate by physical or other relationships in CLCA [95]. Dalgaard et al. [97] then performed a CLCA of soybean meal and avoided allocation by applying the substitution of marginal vegetable oil [97]. The fifth article of this period, authored by Thomassen et al., compares attributional and consequential LCAs of milk production [98]. They showed that depending on the modeling approach (ALCA or CLCA), the results significantly vary for the same system because of the different ways of dealing with multifunctionality (allocation versus system expansion with substitution). In the middle of this period, ISO 14044:2006 was released.

\subsection{ISO 14044:2006 Application (from 2009)}

At this stage, the most cited article identified by the search was published by Finnveden et al. [99]. This article repeated that the underlying physical relationships of ISO14044:2006's second hierarchy level should represent physical, chemical, or biological causation (as also specified before in [73]). Consequently, economic, mass, or energy allocations were intended to be used only as the third level option [99].

Following the main path, we found an LCA on a bio-based plastic product derived from a blood meal [100]. Bier et al. highlighted how different approaches for solving allocation issues in LCAs of bio-based materials could widely vary the results. The next two articles of the main research path discussed the choice of allocation approaches to use in LCAs aimed at informing policy-making. Wardenaar et al. [101] pointed out that methodological uncertainty within ISO led to significantly different results due to the influence of the allocation approach, and argued that the policy context could benefit from new guidelines [101]. Concerning the ISO hierarchy, they stated that "several authors have argued that substitution is equivalent to system expansion" referring as an example to [88]. However, "conceptually equivalent does not mean that system expansion and substitution provide the same results" because there are "large differences between these two methods" [101]. As a consequence of this assumed conceptual equivalency, some authors "use this implicit argument to choose for substitution, while still claiming compliance to ISO" [101]. Concerning allocation based on a physical parameter, Wardenaar et al. argued that the physical parameter should be the one reflecting the physical characteristics related to "the purpose or use of the product", i.e., the relevant characteristic for which they are sold [101].

Following the main path, we found a study on the Environmental Footprint guidelines published by the European Commission [65]. The study of 2014 of Pelletier et al. [65] highlighted that in ISO's first level system expansion, the functional unit is expanded to include the other co-functions (enlargement), 
and the impacts are therefore reported at the system level, i.e., at the level of all co-products [65]. This was claimed to be the "literal interpretation of ISO 14044" [9]. Accordingly, the PEF guide [28] does not consider substitution as a system expansion approach, but only enlargement (similarly the more recent PEFCR guidance [29]). However, the ILCD handbook allows system reduction as an option in CLCA, and for those ALCAs whose aim is to include also the interactions with other systems [27].

The key-route main path analysis allowed us to identify the origins of the "equivalency" substitution-system expansion, i.e., the articles on the side of the bilateral beginning period originated by Tillman et al. [58]. The suggestion of Pelletier et al. [9] that this equivalency originated from the 1994 study of Tillman et al. [58] was therefore confirmed by our analysis. Nevertheless, the article by Tillman et al. [58] was published before any ISO standard and, therefore, did not refer to the system expansion method as intended by ISO.

In the next publication of the main path, Pelletier et al. (2015) observed that, despite the ISO hierarchy, consistent implementation of this hierarchy in the literature was limited, and presented the three schools of thought (consequential, socio-economic ALCA and natural-science ALCA) mentioned at the beginning of Section 3 .

The next two articles in the main research path were focused on finding allocation parameters for agricultural systems. The first article proposed an allocation based on plant physiological construction cost for plant compounds, which should represent the underlying physical relationships between co-products, i.e., the physiological mechanism involved in plant growth [102]. Hence, they concluded that, according to ISO, such a method should be preferred to allocation based on common properties of co-products, such as energy or economic content [102]. Subsequently, Mackenzie et al. [69] studied similar biophysical allocation methods and concluded instead that these methods might not represent the causal physical mechanisms of these systems because they overlook the interconnectivity between co-products [69] as instead, an LP would do. Therefore, they concluded that allocation by economics is preferable [69]. Mackenzie et al. also pointed out that many practitioners often choose an allocation based on an arbitrary parameter (e.g., their mass or energy content) also when it does not reflect such a cause-effect mechanism [69].

The last two articles of the main path were focused on how to allocate burdens to by-products which were previously considered wastes $[103,104]$. These by-products are scarce wastes that can be converted into valuable products. In particular, Pradel et al. constructed a novel allocation method based on relevant causal relationships obtained by mathematical modeling [103]. This model was applied to wastewater treatment plants delivering sludge (by-product) and clean water (main product) and calculated the allocation factor for sludge and water.

\section{Discussion and Conclusions}

Despite the existence of a hierarchy for solving multifunctionality in ISO 14044:2006, the complexity of the multifunctionality problem, the lack of sufficient guidance, its difficult interpretation, and the discrepancies in other "ISO-compliant" guides or handbooks have led to a wide variety of allocation procedures in the literature. Such variety is especially present in the system expansion approaches and in the choice of the allocation key.

ISO 14044:2006 does not distinguish between attributional and consequential modeling. For many practitioners, distinguishing between attributional or consequential LCAs is a crucial key to selecting the method to deal with multifunctionality. For other practitioners, some mixed approaches can be considered as advancements in the methodology. We found that only $25 \%$ of the LCAs clearly state the approach followed using the terms "attributional" and "consequential". Are practitioners not specifying it because they assume it to be "intrinsically clear" from the goal description, or because they do not agree with such a distinction? Some mixed approaches have also been proposed in the literature.

The first major reason for debate on ISO's multifunctionality hierarchy is the application of substitution as a system expansion method in ALCA (found in 31\% of the self-declared attributional studies explored through text mining). Such practice is perceived as inappropriate by many practitioners. 
However, some practitioners who do not acknowledge substitution as system expansion in ALCA recognize the use of substitution as an allocation method for ALCA. Concerning the use of substitution, another aspect that many practitioners pointed out is that a future ISO standard should emphasize more the criterion of physical/economical significance as a prerequisite to apply substitution to avoid incorrect interpretations of the results.

The second reason for the debate is the meaning and application of the "ISO relationships" criterion for the selection of the allocation method. A first interpretation (found in $28 \%$ of the case studies) is that the ISO refers to "causal physical relationships" as relationships mathematically modeled, while "other causal relationships" relate to other relationships (e.g., based on physical or economic parameters) selected based on the best proxy for physical relationships. The second interpretation is that allocation by "physical relationships" refers to an allocation by physical parameters (e.g., mass or energy) while "other relationships" refer to economic relationships.

Most (94\%) of the LCAs of multifunctional case studies found in the literature search are linked to bioeconomy (agriculture, biofuels, bioenergy, and biomaterials) and its linked sectors (fossil fuels and petrochemical plastic materials and dairy products). This has generated inconsistencies within each area, but also at the boundaries between these sectors, because of their multiple links. As an example, biogas can be produced from the manure of a farm, which produces dairy products with animals that eat dried distillers' grains with solubles coming from ethanol fermentation. Such ethanol production may have a pre-treatment process shared with lactic acid fermentation. This lactic acid may be used to produce poly-lactide which, in the market, replaces polypropylene. The above biogas can then be used to generate electricity that can be partly consumed on the farm and partially injected in the grid, substituting power from fossil fuels. How much double counting or how many inconsistencies arise when ISO 14044:2006 is interpreted differently in each of these sectors?

The bibliometric review based on the analysis of the main path obtained from tracing the citation network allowed us to (1) reconstruct how the implementation practices of the ISO hierarchy developed in the last 25 years, (2) identify the origin of the different interpretations and their rationales, and (3) understand how the discrepancies found in the critical review were generated. It emerged that, originally, the ISO hierarchy [92] recommended the approach followed by the "socio-economic ALCA school". The socio-economic ALCA school interprets system expansion as enlargement but prefers economic allocation to allocation based on physical parameters representing a proxy for causality. The origin of the "natural-science ALCA school" was traced to ISO 14041:1998 [25], when allocation by physical parameter as well as economic allocation was permitted as an example of ISO "allocation by other relationships". The natural-science ALCA school interprets system expansion as enlargement and applies allocation based on a physical parameter (for a part of the practitioners subscribing to this view, this choice is justified only when a physical parameter representing causality principles is identified). Its role was promoted by the release of the PEF guide and PEFCR guidance [28,29], which expressed a preference for allocation based on physical parameters over economic ones. Another important view is the one of the "CLCA school" interpreting system expansion as substitution and selecting the allocation method based on causality principles. The birth and development of the CLCA school were found in the annex of ISO14041:1998 and in the publications of Ekvall and co-authors [72,88,94]. They were the first ones (in the main path) to acknowledge the suitability of the substitution method to avoid allocation and account for counterfactual effects (originally proposed by Tillman et al. [58]) and the assumption of "conceptual equivalency" of substitution with the system expansion method.

Summarizing, following one or the other school of thought, a different method is often preferred for the same system, goal and decision context. Applying these different methods could lead to different conclusions and, sometimes, opposite conclusions.

To increase the consistency and reliability of LCA, we believe that a future revised ISO should:

1. Clearly state if distinguishing between attributional and consequential LCA is a key principle to implement the hierarchy. If yes, then it should differentiate the hierarchy for the two approaches and clarify if the hierarchy allows substitution as a system expansion method in attributional LCAs. 
2. Clarify the meaning of allocation by "physical relationships" and "other relationships", providing more examples and details than the ones reported in ISO 14044:2006 and ISO 14049:2012.

Author Contributions: Conceptualization, C.M. and B.C.; methodology, C.M., B.C., A.M. and M.R.; software, C.M.; validation, C.M., B.C., R.E., M.J. and L.S.; formal analysis, C.M., B.C., R.E. and M.R.; investigation, C.M., R.E., A.M.; resources, A.M., M.R. and L.S.; data curation, C.M., B.C., M.J., L.S.; writing-original draft preparation, C.M., B.C., R.E.; writing-review and editing, R.E., M.J., A.M., M.R. and L.S.; visualization, B.C., L.S.; supervision, B.C., M.J., A.M., M.R. and L.S.; All authors have read and agreed to the published version of the manuscript.

Funding: This research received no external funding

Conflicts of Interest: The authors declare no conflict of interest.

\section{Appendix A}

\section{Appendix A.1. Type of Products}

In this article, three definitions are used for different types of products and services: co-products, by-products and wastes.

Co-products are the ones satisfying the main (primary) function that a production system or process is intended to deliver. As highlighted by Majeau-Bettez et al. [35], co-products have also been defined with the term "primary", "determining", and others. Conversely, by-products represent only secondary functions of the system. A by-product is a substance resulting from a production process whose primary function is not the production of that item but either it is inevitably produced or could, in principle, be avoided by the system without altering the main functionality of the process (e.g., a farm with tourist accommodation services).

The primary function of a product system is identified by evaluating the purpose of such a system. For example, for the internal combustion engine of a car, the primary product is the mechanical power needed by the car to carry people (primary function). A secondary function of the same engine can be the production of heating (by-product) to keep a proper temperature in the car. Nevertheless, the distinction between primary and secondary functions can be particularly difficult for some unit processes (e.g., sunflower oil vs meal). When such difficulty is encountered, the primary function should be selected by assessing what function of the multifunctional process generates more revenues for the investigated process $[27,35,63]$, within the temporal scope of the LCA. Nevertheless, there are processes whose aim is the generation of several functions of comparable value. In such a case, there can be multiple primary functions. For example, a biorefinery can produce various chemicals and fuels as primary functions (co-products) and provide district heating as a secondary function (by-product).

The shared environmental impact of a process shall be apportioned between co-products and by-products, but not to wastes [2]. According to ISO 14044:2006, wastes are "substances or objects which the holder intends or is required to dispose of" [2]. There is, however, a fine line between wastes and by-products. For example, manure is nowadays used as feedstock for biogas plants, used cooking oil is used for biodiesel production, and residues of the potato industry are used for animal feed. When these alternative uses make these wastes find a market demand represented by market values, they should be considered, therefore, as by-products. We adopt the distinction waste/by-product provided by the Waste Directive Framework [105]. A "waste" becomes a by-product when the "following conditions are met: (1) further use of the substance or object is certain; (2) the substance or object can be used directly without any further processing other than normal industrial practice; (3) the substance or object is produced as an integral part of a production process; (4) further use is lawful, i.e., the substance or object fulfills all relevant product, environmental and health protection requirements for the specific use and will not lead to overall adverse environmental or human health impacts" [105]. 


\section{Appendix A.2. Type of Multifunctional Processes}

As highlighted by several authors, the terminology reported in the literature for distinguishing the different types of multifunctional processes is not harmonized [5,35]. This article follows the terminology defined by Majeau-Bettez et al. [35], who differentiated between full-joint production, partial joint production, and combined production. Full joint production takes place when the co-products are produced simultaneously, with a fixed ratio of production (e.g., fixed by the stoichiometry of a chemical reaction, or by natural processes such as the proportions between wheat grains and wheat straw). Partial joint production occurs when there is an intermediate level of technological linkage between the different co- and by-products (e.g., an oil refinery as a whole or the production of milk and meat or the transportation of two different products) and combined production when there is not technological linkage (e.g., a gasoline station also offering shop services). According to this definition, the ratio of production of the co- and by-products could be varied in every case except for the full joint production.

\section{Appendix A.3. Type of Modeling Approaches}

The selection of the modeling approach is based on the goal of the study and the decision context. Generally, when the goal of a study is to describe the status of a system, an attributional LCA (ALCA) approach is followed to calculate the environmental impact of providing a specific amount of the functional unit [5]. When the goal is to describe the effect of a change due to a decision, a consequential LCA (CLCA) approach is followed to estimate how this environmental impact would change in response to a change in the output of the functional unit (i.e., it is change-oriented) [98]. The current conceptualization of the CLCA approach was first publicly discussed in the 2001 international workshop on electricity data for life cycle inventories [106].

One of the main principles of ALCA is the so-called 100\% additivity [35]. This principle means that "results of a separate analysis of all economic activities should add up to the result of an analysis of the total economic activity" [39], so ALCA is suitable for attributing the total impacts to a defined function (product or service), but, for example, it does not indicate to policy makers the impact of policy changes, when these cause an incremental change from the status quo.

By contrast, CLCA determines the change in impacts due to a change in the production of the product or service, or to a change in policy. So it attempts to consider all the impacts of the change, also on other sectors that are influenced, for example as a consequence of the use of by-products [35]. CLCA is therefore preferred to ALCA for estimating the impact of policy changes [107]. CLCA usually uses market-driven modeling to forecast what will happen once the product or service of interest is introduced [59]. This means that in CLCA, marginal processes are considered, rather than average ones, including the activities displaced by by-products. This is typically modeled through the so-called substitution approach, whereby CLCA considers only the activities reacting to the change in demand for the functional unit, keeping the total of other services constant. Therefore, the quantification of displaced activities depends on the market characteristics of competing products [14].

\section{Appendix A.4. Type of System Expansion Approach and Substitution}

System expansion means the enlargement of the boundaries of the system under investigation to include additional processes and functions. As mentioned above, expansion of the boundaries can be used to avoid allocation. There are two possible approaches to avoid allocation by expanding the boundaries: enlargement (see Figure A1 for different types of enlargement) and substitution (see Figure A2). By considering the subtraction as "a negative addition" [51], substitution is considered by some LCA practitioners as a form of system expansion used to isolate the impact of just one function from a multifunctional process.

One can apply system enlargement by modifying the functional unit to include all co-functions (case a of Figure A1). This approach is not possible when the goal of the study requires to determine the impacts of only one of the products because the results at the level of one single product would not be 
available. System enlargement is also often used for comparative assessments. In case b of Figure A1, the aim is to compare process P1 (providing functions A and B) with process P2 (providing only function A). One needs to add to $\mathrm{P} 2$ another process for producing $\mathrm{B}$ in order to allow the comparison for the same outputs. Similarly, in case d of Figure A1, the aim is to compare a process producing A with a process producing B (for example, comparing the impacts of two products which could be made from the same raw material). In this case, one needs to add alternative processes for making both $A$ and B in order to make a meaningful comparison. Even though these processes are not initially multifunctional, system enlargement is applied to allow for a fair comparison. One can also apply system enlargement in open-loop recycling systems. In the example of system enlargement from ISO/TR 14049, open-loop recycling is solved with a closed-loop procedure that includes the entire recycling processes into the same system boundaries (like case c of Figure A1).

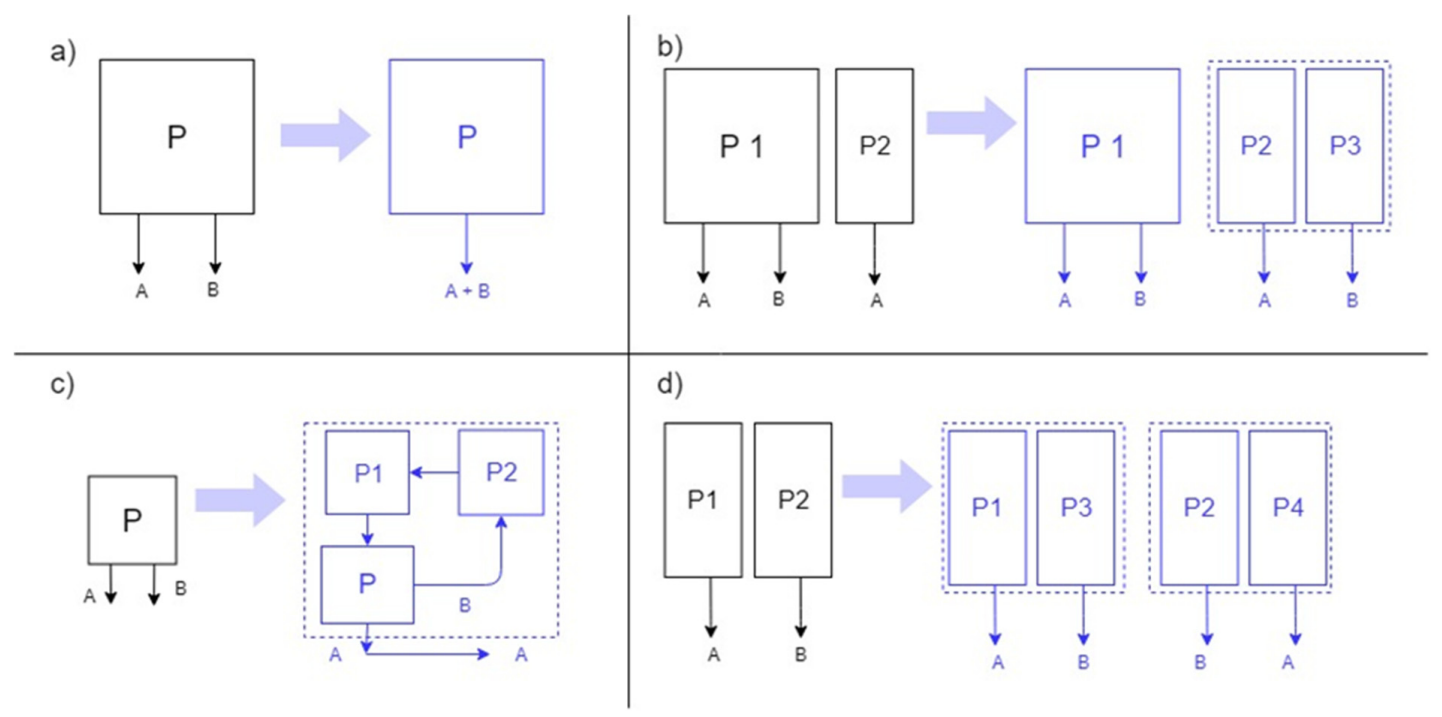

Figure A1. Different ways to apply system expansion as enlargement-addition of functions. In black: multifunctional process before applying system expansion. In blue: process after the expansion of the boundaries/addition of functions. (a) Changing the FU to avoid allocation. (b) Adding extra processes (P3, delivering B) to a system ( $\mathrm{P} 2$, delivering $\mathrm{A}$ ) that is compared with another system (P1) delivering several functions (A and B). (c) Applying closed-loop recycling to a system (P) where one of the outputs (B) is used as a material input in the same product system (P2 represents the intermediate processing of $\mathrm{B}$ that allows its re-use). (d) Adding extra processes (P3 and P4) to compare systems that provide different functions and that at the beginning were not multifunctional.

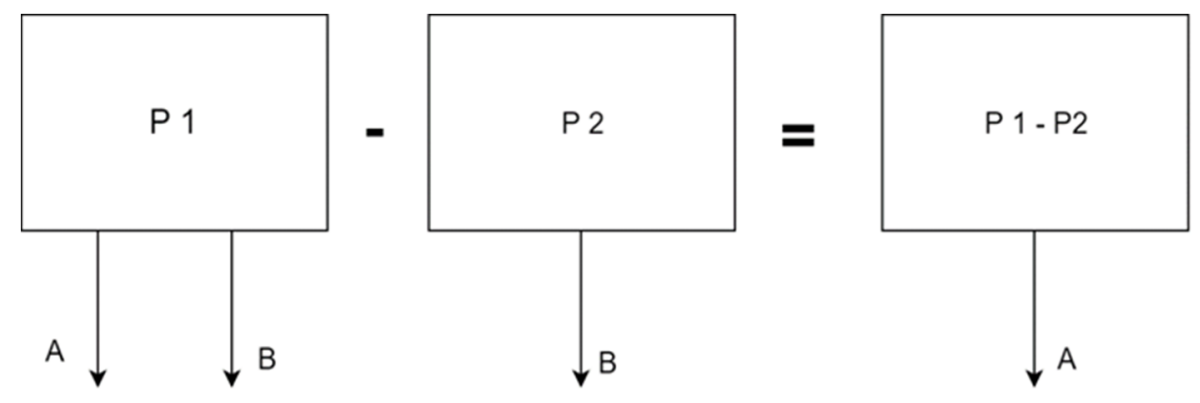

Figure A2. System expansion by substitution (reduction of functions). The investigated system (P1) delivers two products (A and B). Alternatively, product B can be produced by another system (P2). The substitution method proposes that the impact of producing A (only) by process P1, corresponds to the difference of impact between P1 and P2. 


\section{References}

1. ISO (International Standard Organization). ISO 14040: Environmental Management_Life Cycle AssessmentPrinciples and Framework; Technical Committee ISO/TC 207; ISO: Geneva, Switzerland, 2006.

2. ISO (International Standard Organization). ISO 14044, Environmental Management_Life Cycle AssessmentRequirements and Guidelines; ISO/TC 207/SC 5; ISO: Geneva, Switzerland, 2006.

3. Sandin, G.; Røyne, F.; Berlin, J.; Peters, G.M.; Svanström, M. Allocation in LCAs of biorefinery products: Implications for results and decision-making. J. Clean. Prod. 2015, 93, 213-221. [CrossRef]

4. Zamagni, A.; Buttol, P.; Porta, P.L.; Buonamici, R.; Masoni, P.; Guinée, J.; Heijungs, R.; Ekvall, T.; Bersani, R.; Bieńkowska, A.; et al. Critical Review of the Current Research Needs and Limitations Related to ISO-LCA Practice; Enea: Rome, Italy, 2008.

5. Schrijvers, D.L.; Loubet, P.; Sonnemann, G. Developing a systematic framework for consistent allocation in LCA. Int. J. Life Cycle Assess. 2016, 21, 976-993. [CrossRef]

6. Reap, J.; Roman, F.; Duncan, S.; Bras, B. A survey of unresolved problems in life cycle assessment. Part 1: Goal and scope and inventory analysis. Int. J. Life Cycle Assess. 2008, 13, 290-300. [CrossRef]

7. Weidema, B. Avoiding Co-Product Allocation in Life-Cycle Assessment. J. Ind. Ecol. 2000, 4, 11-33. [CrossRef]

8. Muench, S.; Guenther, E. A systematic review of bioenergy life cycle assessments. Appl. Energy 2013, 112, 257-273. [CrossRef]

9. Pelletier, N.; Ardente, F.; Brandão, M.; De Camillis, C.; Pennington, D. Rationales for and limitations of preferred solutions for multi-functionality problems in LCA: Is increased consistency possible? Int. J. Life Cycle Assess. 2015, 20, 74-86. [CrossRef]

10. Agostini, A.; Giuntoli, J.; Marelli, L.; Amaducci, S. Flaws in the interpretation phase of bioenergy LCA fuel the debate and mislead policymakers. Int. J. Life Cycle Assess. 2019, 25, 17-35. [CrossRef]

11. Lloyd, S.M.; Ries, R. Characterizing, propagating, and analyzing uncertainty in life-cycle assessment: A survey of quantitative approaches. J. Ind. Ecol. 2007, 11, 161-179. [CrossRef]

12. Klöpffer, W. The critical review of life cycle assessment studies according to ISO 14040 and 14044. Int. J. Life Cycle Assess 2012, 17, 1087-1093. [CrossRef]

13. Moretti, C.; Junginger, M.; Shen, L. Environmental life cycle assessment of polypropylene made from used cooking oil. Resour. Conserv. Recycl. 2020, 157, 104750. [CrossRef]

14. Brando, M.; Martin, M.; Cowie, A.; Hamelin, L.; Zamagni, A. Consequential Life Cycle Assessment: What, How, and Why? Encycl. Sustain. Technol. 2017, 1, 277-284.

15. Benetto, E.; Jury, C.; Kneip, G.; Vázquez-Rowe, I.; Huck, V.; Minette, F. Life cycle assessment of heat production from grape marc pellets. J. Clean. Prod. 2015, 87, 149-158. [CrossRef]

16. Zaimes, G.G.; Khanna, V. The role of allocation and coproducts in environmental evaluation of microalgal biofuels: How important? Sustain. Energy Technol. Assess. 2014, 7, 247-256. [CrossRef]

17. Śliwińska, A.; Burchart-Korol, D.; Smoliński, A. Environmental life cycle assessment of methanol and electricity co-production system based on coal gasification technology. Sci. Total Environ. 2017, 574, 1571-1579. [CrossRef]

18. Bava, L.; Bacenetti, J.; Gislon, G.; Pellegrino, L.; D’Incecco, P.; Sandrucci, A.; Tamburini, A.; Fiala, M.; Zucali, M. Impact assessment of traditional food manufacturing: The case of Grana Padano cheese. Sci. Total Environ. 2018, 626, 1200-1209. [CrossRef]

19. Esteves, V.P.; Esteves, E.M.; Bungenstab, D.J.; Feijó, G.L.; Araújo, O.D.; Morgado, C.D. Assessment of greenhouse gases (GHG) emissions from the tallow biodiesel production chain including land use change (LUC). J. Clean. Prod. 2017, 151, 578-591. [CrossRef]

20. Pa, A.; Craven, J.S.; Bi, X.T.; Melin, S.; Sokhansanj, S. Environmental footprints of British Columbia wood pellets from a simplified life cycle analysis. Int. J. Life Cycle Assess. 2012, 17, 220-231. [CrossRef]

21. Liu, J.S.; Chen, H.H.; Ho, M.H.C.; Li, Y.C. Citations with different levels of relevancy: Tracing the main paths of legal opinions. J. Assoc. Inf. Sci. Technol. 2014, 65, 2479-2488. [CrossRef]

22. Xiao, Y.; Lu, L.Y.Y.; Liu, J.S.; Zhou, Z. Knowledge diffusion path analysis of data quality literature: A main path analysis. J. Informetr. 2014, 8, 594-605. [CrossRef]

23. ISO (International Standard Organization). TECHNICAL REPORT ISO/TR 14049 Environmental ManagementLife Cycle Assessment-Examples of Application of ISO 14041 to Goal and Scope Definition and Scope Definition and Inventory Analysis; ISO: Geneva, Switzerland, 2006. 
24. ISO (International Standard Organization). ISO/TR 14049:2012. Environmental Management_Life Cycle AssessmentIllustrative Examples on How to Apply ISO 14044 to Goal and Scope Definition and Inventory Analysis; ISO: Geneva, Switzerland, 2006.

25. ISO (International Standard Organization). ISO 14041. Environmental Management_Life Cycle AssessmentGoal and Scope Definition and Inventory Analysis; ISO: Geneva, Switzerland, 1998.

26. ISO (International Standard Organization). ISO/TS 14072:2014. Environmental Management-Life Cycle Assessment_-Requirements and Guidelines for Organizational Life Cycle Assessment; ISO: Geneva, Switzerland, 2014.

27. ILCD. ILCD Handbook-General guide on LCA-Detailed guidance. Constraints 2010, 15, 524-525.

28. Manfredi, S.; Allacker, K.; Pelletier, N.; Chomkhamsri, K.; de Souza, D.M. European Commission Product Environmental Footprint (PEF) Guide; European Commission-Joint Research Centre: Ispra, Italy, 2012; p. 154.

29. European Commission. PEFCR Guidance Document Guidance for the Development of Product Environmental Footprint Category Rules (PEFCRs), Version 6.3 ed; European Commission: Brussels, Belgium, 2017; p. 2018.

30. Moro, A.; Joanny, G.; Moretti, C. Emerging technologies in the renewable energy sector: A comparison of expert review with a text mining software. Futures 2020, 117, 102511. [CrossRef]

31. Batagelj, V.; Mrvar, A. Pajek—analysis and visualization of large networks. In Graph Drawing Software; Springer: Berlin/Heidelberg, Germany, 2011; ISBN 978-3-540-45848-7.

32. Ciano, M.P.; Strozzi, F.; Minelli, E.; Pozzi, R.; Rossi, T. The link between lean and human resource management or organizational behaviour: A bibliometric review. In Proceedings of the XXIV Summer School "Francesco Turco"-Industrial Systems Engineering, Brescia, Italy, 11-13 September 2019; pp. 321-328.

33. Strozzi, F.; Colicchia, C.; Creazza, A.; Noè, C. Literature review on the 'smart factory' concept using bibliometric tools. Int. J. Prod. Res. 2017, 55, 6572-6591. [CrossRef]

34. Liu, J.S.; Lu, L.Y.Y. An integrated approach for main path analysis: Development of the Hirsch index as an example. J. Am. Soc. Inf. Sci. Technol. 2012, 63, 528-542. [CrossRef]

35. Majeau-Bettez, G.; Dandres, T.; Pauliuk, S.; Wood, R.; Hertwich, E.; Samson, R.; Strømman, A.H. Choice of allocations and constructs for attributional or consequential life cycle assessment and input-output analysis. J. Ind. Ecol. 2018, 22, 656-670. [CrossRef]

36. De Camillis, C.; Brandão, M.; Zamagni, A.; Pennington, D. Sustainability Assessment of Future-Oriented Scenarios: A Review of Data Modelling Approaches in Life Cycle Assessment. Towards Recommendations for Policy Making and Business Strategies; Publications Office of the European Union: Luxemburg, 2013; ISBN 9789279325229.

37. Sandin, G.; Peters, G.M.; Svanström, M. Life cycle assessment of construction materials: The influence of assumptions in end-of-life modelling. Int. J. Life Cycle Assess. 2014, 19, 723-731. [CrossRef]

38. Peñaloza, D.; Erlandsson, M.; Falk, A. Exploring the climate impact effects of increased use of bio-based materials in buildings. Constr. Build. Mater. 2016, 125, 219-226. [CrossRef]

39. Heijungs, R. Economic Drama and the Environmental Stage: Formal Derivation of Algorithmic Tools for Environmental Analysis and Decisionsupport from a Unified Epistemological Principle; Leiden University: Leiden, The Netherlands, 1997.

40. Chen, C.; Habert, G.; Bouzidi, Y.; Jullien, A.; Ventura, A. LCA allocation procedure used as an incitative method for waste recycling: An application to mineral additions in concrete. Resour. Conserv. Recycl. 2010, 54, 1231-1240. [CrossRef]

41. Bailis, R.; Kavlak, G. Environmental implications of Jatropha biofuel from a silvi-pastoral production system in central-west Brazil. Environ. Sci. Technol. 2013, 47, 8042-8050. [CrossRef]

42. Schau, E.M.; Fet, A.M. LCA studies of food products as background for environmental product declarations. Int. J. Life Cycle Assess. 2008, 13, 255-264. [CrossRef]

43. Heijungs, R.; Guinée, J.B. Allocation and "what-if" scenarios in life cycle assessment of waste management systems. Waste Manag. 2007, 27, 997-1005. [CrossRef]

44. Heijungs, R. Ten easy lessons for good communication of LCA. Int. J. Life Cycle Assess. 2014, 19, 473-476. [CrossRef]

45. Marvuglia, A.; Cellura, M.; Heijungs, R. Toward a solution of allocation in life cycle inventories: The use of least-squares techniques. Int. J. Life Cycle Assess. 2010, 15, 1020-1040. [CrossRef]

46. Steubing, B.; Wernet, G.; Reinhard, J.; Bauer, C.; Moreno-Ruiz, E. The ecoinvent database version 3 (part II): Analyzing LCA results and comparison to version 2. Int. J. Life Cycle Assess. 2016, 21, 1269-1281. [CrossRef] 
47. Nguyen, T.L.T.; Hermansen, J.E. System expansion for handling co-products in LCA of sugar cane bio-energy systems: GHG consequences of using molasses for ethanol production. Appl. Energy 2012, 89, 254-261. [CrossRef]

48. Corrado, S.; Ardente, F.; Sala, S.; Saouter, E. Modelling of food loss within life cycle assessment: From current practice towards a systematisation. J. Clean. Prod. 2017, 140, 847-859. [CrossRef]

49. Brander, M.; Wylie, C. The use of substitution in attributional life cycle assessment. Greenh. Gas Meas. Manag. 2011, 1, 161-166. [CrossRef]

50. Nhu, T.T.; Dewulf, J.; Serruys, P.; Huysveld, S.; Nguyen, C.V.; Sorgeloos, P.; Schaubroeck, T. Resource usage of integrated Pig-Biogas-Fish system: Partitioning and substitution within attributional life cycle assessment. Resour. Conserv. Recycl. 2015, 102, 27-38. [CrossRef]

51. Weidema, B. ISO System Expansion = Substitution 2.0. 2014. Available online: https://lca-net.com/blog/isosystem-expansion-substitution/ (accessed on 15 November 2019).

52. Forman, G.S.; Hahn, T.E.; Jensen, S.D. Greenhouse gas emission evaluation of the GTL pathway. Environ. Sci. Technol. 2011, 45, 9084-9092. [CrossRef]

53. Manninen, K.; Koskela, S.; Nuppunen, A.; Sorvari, J.; Nevalainen, O.; Siitonen, S. The applicability of the renewable energy directive calculation to assess the sustainability of biogas production. Energy Policy 2013, 56, 549-557. [CrossRef]

54. Karlsson, H.; Börjesson, P.; Hansson, P.A.; Ahlgren, S. Ethanol production in biorefineries using lignocellulosic feedstock-GHG performance, energy balance and implications of life cycle calculation methodology. J. Clean. Prod. 2014, 83, 420-427. [CrossRef]

55. García, C.A.; Fuentes, A.; Hennecke, A.; Riegelhaupt, E.; Manzini, F.; Masera, O. Life-cycle greenhouse gas emissions and energy balances of sugarcane ethanol production in Mexico. Appl. Energy 2011, 88, 2088-2097. [CrossRef]

56. Li, X.; Mupondwa, E. Life cycle assessment of camelina oil derived biodiesel and jet fuel in the Canadian Prairies. Sci. Total Environ. 2014, 481, 17-26. [CrossRef] [PubMed]

57. Brockmann, D.; Pradinaud, C.; Champenois, J.; Benoit, M.; Hélias, A. Environmental assessment of bioethanol from onshore grown green seaweed. Biofuels Bioprod. Biorefining 2015, 9, 696-708. [CrossRef]

58. Tillman, A.M.; Ekvall, T.; Baumann, H.; Rydberg, T. Choice of system boundaries in life cycle assessment. J. Clean. Prod. 1994, 2, 21-29. [CrossRef]

59. Giuntoli, J.; Commission, E.; Bulgheroni, C.; Commission, E.; Marelli, L.; Commission, E.; Sala, S.; Commission, E. Brief on the use of Life Cycle Assessment (LCA) to evaluate environmental impacts of the bioeconomy. J. Sustain. Energy Environ. Spec. Issue 2019, 1-8. [CrossRef]

60. Cherubini, E.; Franco, D.; Zanghelini, G.M.; Soares, S.R. Uncertainty in LCA case study due to allocation approaches and life cycle impact assessment methods. Int. J. Life Cycle Assess. 2018, 23, 2055-2070. [CrossRef]

61. Herrmann, I.T.; Jørgensen, A.; Bruun, S.; Hauschild, M.Z. Potential for optimized production and use of rapeseed biodiesel. Based on a comprehensive real-time LCA case study in Denmark with multiple pathways. Int. J. Life Cycle Assess. 2013, 18, 418-430. [CrossRef]

62. Forman, G.S.; Hauser, A.B.; Adda, S.M. Life cycle analysis of gas to liquids (GTL) derived linear alkyl benzene. J. Clean. Prod. 2014, 80, 30-37. [CrossRef]

63. Weidema, B.P.; Frees, N.; Nielsen, A.M. Marginal production technologies for life cycle inventories. Int. J. Life Cycle Assess. 1999, 4, 48-56. [CrossRef]

64. Hermansson, F.; Janssen, M.; Svanström, M. Allocation in life cycle assessment of lignin. Int. J. Life Cycle Assess. 2020. Article in Press. [CrossRef]

65. Pelletier, N.; Allacker, K.; Pant, R.; Manfredi, S. The European Commission Organisation Environmental Footprint method: Comparison with other methods, and rationales for key requirements. Int. J. Life Cycle Assess. 2014, 19, 387-404. [CrossRef]

66. Cherubini, F.; Strømman, A.H.; Ulgiati, S. Influence of allocation methods on the environmental performance of biorefinery products-A case study. Resour. Conserv. Recycl. 2011, 55, 1070-1077. [CrossRef]

67. Moretti, C.; Corona, B.; Rühlin, V.; Götz, T.; Junginger, M.; Brunner, T.; Obernberger, I.; Shen, L. Combining biomass gasification and solid oxid fuel cell for heat and power generation: An early-stage life cycle assessment. Energies 2020, 13, 2773. [CrossRef]

68. Ahlgren, S.; Björklund, A.; Ekman, A.; Karlsson, H.; Berlin, J.; Börjesson, P.; Ekvall, T.; Finnveden, G.; Janssen, M.; Strid, I. Review of methodological choices in LCA of biorefinery systems-Key issues and recommendations. Biofuels Bioprod. Biorefining 2015, 9, 606-619. [CrossRef] 
69. Mackenzie, S.G.; Leinonen, I.; Kyriazakis, I. The need for co-product allocation in the life cycle assessment of agricultural systems-Is "biophysical” allocation progress? Int. J. Life Cycle Assess. 2017, 22, 128-137. [CrossRef]

70. Azapagic, A.; Clift, R. Allocation of environmental burdens in multiple-function systems. J. Clean. Prod. 1999, 7, 101-119. [CrossRef]

71. Azapagic, A.; Clift, R. Allocation of environmental burdens in co-product systems: Process and productrelated burdens (part 2). Int. J. Life Cycle Assess. 2000, 5, 31-36. [CrossRef]

72. Ekvall, T.; Finnveden, G. Allocation in ISO 14041-A critical review. J. Clean. Prod. 2001, 9, 197-208. [CrossRef]

73. Azapagic, A.; Clift, R. Linear programming as a tool in life cycle assessment. Int. J. Life Cycle Assess. 1998, 3, 305-316. [CrossRef]

74. Bernier, E.; Lavigne, C.; Robidoux, P.Y. Life cycle assessment of kraft lignin for polymer applications. Int. J. Life Cycle Assess. 2013, 18, 520-5288. [CrossRef]

75. González-García, S.; Moreira, M.T.; Feijoo, G. Environmental performance of lignocellulosic bioethanol production from alfalfa stems. Biofuels Bioprod. Biorefining 2010, 4, 118-131. [CrossRef]

76. Finnveden, G.; Albertsson, A.C.; Berendson, J.; Eriksson, E.; Höglund, L.O.; Karlsson, S.; Sundqvist, J.O. Solid waste treatment within the framework of life-cycle assessment. J. Clean. Prod. 1995, 3, 189-199. [CrossRef]

77. Jungmeier, G.; Werner, F.; Jarnehammar, A.; Hohenthal, C.; Richter, K. Allocation in LCA of wood-based products-Experiences of cost action E9: Part II. Examples. Int. J. Life Cycle Assess. 2002, 7, 290-294. [CrossRef]

78. Nejad, A.T.M.; Saint-Antonin, V. Factors driving refinery $\mathrm{CO}_{2}$ intensity, with allocation into products: Comment. Int. J. Life Cycle Assess. 2014, 19, 24-28.

79. Moretti, C.; Moro, A.; Edwards, R.; Rocco, M.V.; Colombo, E. Analysis of standard and innovative methods for allocating upstream and refinery GHG emissions to oil products. Appl. Energy 2017, 206, 372-381. [CrossRef]

80. International Dairy Federation. A Common Carbon Footprint Approach for Dairy: The IDF Guide to Standard Lifecycle Assessment Methodology for the Dairy Sector. 2015. Available online: https://store.fil-idf.org/product/a-common-carbon-footprint-approach-for-the-dairy-sector-the-idfguide-to-standard-life-cycle-assessment-methodology/ (accessed on 10 July 2020).

81. Van der Harst, E.; Potting, J.; Kroeze, C. Comparison of different methods to include recycling in LCAs of aluminium cans and disposable polystyrene cups. Waste Manag. 2016, 48, 565-583. [CrossRef] [PubMed]

82. Silva, D.A.L.; Lahr, F.A.R.; Pavan, A.L.R.; Saavedra, Y.M.B.; Mendes, N.C.; Sousa, S.R.; Sanches, R.; Ometto, A.R. Do wood-based panels made with agro-industrial residues provide environmentally benign alternatives? An LCA case study of sugarcane bagasse addition to particle board manufacturing. Int. J. Life Cycle Assess. 2014, 19, 1767-1778. [CrossRef]

83. Palmieri, N.; Forleo, M.B.; Giannoccaro, G.; Suardi, A. Environmental impact of cereal straw management: An on-farm assessment. J. Clean. Prod. 2017, 142, 2950-2964. [CrossRef]

84. Vergé, X.; Maxime, D.; Desjardins, R.L.; Vanderzaag, A.C. Allocation factors and issues in agricultural carbon footprint: A case study of the Canadian pork industry. J. Clean. Prod. 2016, 113, 587-595. [CrossRef]

85. Tufvesson, L.M.; Tufvesson, P.; Woodley, J.M.; Börjesson, P. Life cycle assessment in green chemistry: Overview of key parameters and methodological concerns. Int. J. Life Cycle Assess. 2013, 18, 431-444. [CrossRef]

86. Vidal, R.; Martínez, P.; Garraín, D. Life cycle assessment of composite materials made of recycled thermoplastics combined with rice husks and cotton linters. Int. J. Life Cycle Assess. 2009, 14, 73-82. [CrossRef]

87. Vera, I.; Hoefnagels, R.; van der Kooij, A.; Moretti, C.; Junginger, M. A carbon footprint assessment of multi-output biorefineries with international biomass supply: A case study for the Netherlands. Biofuels Bioprod. Biorefining 2020, 14, 198-224. [CrossRef]

88. Ekvall, T.; Tillman, A.M. Open-loop recycling: Criteria for allocation procedures. Int. J. Life Cycle Assess. 1997, 2, 155-162. [CrossRef]

89. Clift, R. Chairman's report of session 3: Causality and allocation procedures. In Proceedings of the European Workshop on Allocation in LCA, Leiden, The Netherlands, 24-25 February 1994; pp. 3-4.

90. Clift, R. Report from setac-europe working group on life cycle inventory analysis. In Abstract Book, 6th SETAC-Europe, Proceedings of the Annual Meeting, Taormina, Italy, 19-22 May 1996; SETAC-Europe: Brussels, Belgium, 1996; p. 17.

91. Azapagic, A.; Clift, R. Life cycle assessment and linear programming environmental optimisation of product system. Comput. Chem. Eng. 1995, 19, 229-234. [CrossRef] 
92. ISO (International Standard Organization). ISO/TC 207/SC 5/AXIG2: CD 14 041.2. N99, DIN. 1996 (as Cited by Ekvall and Tillman in Open-loop Recycling: Criteria for Allocation Procedures-[88]); ISO: Geneva, Switzerland, 1996.

93. Azapagic, A.; Clift, R. Allocation of Environmental Burdens in Co-product Systems: Product-related Burdens (Part 1). Int. J. Life Cycle Assess. 1999, 4, 357-369. [CrossRef]

94. Ekvall, T.; Weidema, B.P. System boundaries and input data in consequential life cycle inventory analysis. Int. J. Life Cycle Assess. 2004, 9, 161-171. [CrossRef]

95. Thrane, M. LCA of Danish fish products: New methods and insights. Int. J. Life Cycle Assess. 2006, 11, 66-74. [CrossRef]

96. Schmidt, J.H.; Weidema, B.P. Shift in the marginal supply of vegetable oil. Int. J. Life Cycle Assess. 2008, 13, 235-239. [CrossRef]

97. Dalgaard, R.; Schmidt, J.; Halberg, N.; Christensen, P.; Thrane, M.; Pengue, W.A. LCA for soybean meal. LCA Food Prod. 2008, 10, 240-254. [CrossRef]

98. Thomassen, M.A.; Dalgaard, R.; Heijungs, R.; De Boer, I. Attributional and consequential LCA of milk production. Int. J. Life Cycle Assess. 2008, 13, 339-349. [CrossRef]

99. Finnveden, G.; Hauschild, M.Z.; Ekvall, T.; Guinée, J.; Heijungs, R.; Hellweg, S.; Koehler, A.; Pennington, D.; Suh, S. Recent developments in Life Cycle Assessment. J. Environ. Manag. 2009, 91, 1-21. [CrossRef] [PubMed]

100. Bier, J.M.; Verbeek, C.J.R.; Lay, M.C. An eco-profile of thermoplastic protein derived from blood meal Part 1: Allocation issues. Int. J. Life Cycle Assess. 2012, 17, 208-219. [CrossRef]

101. Wardenaar, T.; Van Ruijven, T.; Beltran, A.M.; Vad, K.; Guinée, J.; Heijungs, R. Differences between LCA for analysis and LCA for policy: A case study on the consequences of allocation choices in bio-energy policies. Int. J. Life Cycle Assess. 2012, 17, 1059-1067. [CrossRef]

102. Van der Werf, H.M.G.; Nguyen, T.T.H. Construction cost of plant compounds provides a physical relationship for co-product allocation in life cycle assessment. Int. J. Life Cycle Assess. 2015, 20, 777-784. [CrossRef]

103. Pradel, M.; Aissani, L.; Canler, J.P.; Roux, J.C.; Villot, J.; Baudez, J.C.; Laforest, V. Constructing an allocation factor based on product- and process-related parameters to assess environmental burdens of producing value-added sludge-based products. J. Clean. Prod. 2018, 171, 1546-1557. [CrossRef]

104. Pradel, M.; Aissani, L. Environmental impacts of phosphorus recovery from a "product" Life Cycle Assessment perspective: Allocating burdens of wastewater treatment in the production of sludge-based phosphate fertilizers. Sci. Total Environ. 2019, 656, 55-69. [CrossRef] [PubMed]

105. European Union Directive 2008/98/EC of the European Parliament and of the Council of 19 November 2008 on Waste and Repealing Certain Directives; LexUriServ; European Union: Brussels, Belgium, 2008.

106. Curran, M.A.; Mann, M.; Norris, G. The international workshop on electricity data for life cycle inventories. J. Clean. Prod. 2005, 13, 853-862. [CrossRef]

107. Plevin, R.J.; Delucchi, M.A.; Creutzig, F. Using Attributional Life Cycle Assessment to Estimate ClimateChange Mitigation Benefits Misleads Policy Makers. J. Ind. Ecol. 2014, 18, 73-83. [CrossRef]

(C) 2020 by the authors. Licensee MDPI, Basel, Switzerland. This article is an open access article distributed under the terms and conditions of the Creative Commons Attribution (CC BY) license (http://creativecommons.org/licenses/by/4.0/). 